\title{
Potential release of aluminum and other metals by food-grade aluminum foil used for skin allograft cryo preservation
}

\author{
Gilbert Verbeken • Dirck Schoeters • Gunther Verween • Daniel De Vos • \\ Bruno Pascual $\cdot$ Peter De Corte $\cdot$ Kris Geukens $\cdot$ Arlette De Coninck • \\ Diane Roseeuw $\cdot$ Thomas Rose $\cdot$ Serge Jennes $\cdot$ Jean-Paul Pirnay
}

Received: 21 September 2009/Accepted: 22 January 2010/Published online: 10 February 2010

(C) The Author(s) 2010. This article is published with open access at Springerlink.com

\begin{abstract}
Since 1991, the skin bank of the Queen Astrid Military Hospital uses food-grade aluminum foil as a primary support for storing cryo preserved human donor skin (511 donors). The possible release of heavy metals into the cryo preservation media $(30 \%(\mathrm{v} / \mathrm{v})$ glycerol in physiological water) and the possible impact this release could have on the quality of the cryo preserved donor skin was evaluated. Aluminum was the principal detection target. Possible contaminants of the aluminum foil as such (arsenic, cadmium, chromium and lead) were also investigated. The evaluation was set up after a Belgian Competent Authority inspection remark. Aluminum was detected at a concentration of $1.4 \mathrm{mg} / \mathrm{l}$, arsenic and lead were not detected, while
\end{abstract}

G. Verbeken $(\bowtie) \cdot$ D. Schoeters · G. Verween ·

D. De Vos - B. Pascual · P. De Corte .

T. Rose - J.-P. Pirnay

LabMCT, Skin- and Keratinocyte Bank, Burn Wound

Centre, Queen Astrid Military Hospital, Brussels,

Belgium

e-mail: gilbert.verbeken@mil.be

K. Geukens

Department for Chemical Analysis, CBRN-Laboratories of the Belgian Ministry of Defense, Peutie, Belgium

\section{A. De Coninck · D. Roseeuw}

Department of Dermatology and Pathology, UZ Brussel,

Vrije Universiteit Brussel, Brussels, Belgium

\section{S. Jennes}

Burn Wound Centre, Queen Astrid Military Hospital, Brussels, Belgium cadmium and chromium were detected in trace element quantities. An histological analysis revealed no differences between cryo preserved and fresh donor skin. No adverse reactions in patients, related to the presence of aluminum or heavy metal traces, were reported since the introduction of the cryo preserved donor skin in our burn wound centre.

Keywords Skin banking - Cryo preservation . Metal release $\cdot$ Food-grade packaging material . Aluminum

\section{Introduction and rationale}

The intertwined quality and safety issues are essential in all medical activities. Also in the fast growing field of tissue and cell banking there is an increased awareness.

The skin bank of the Queen Astrid Military Hospital uses food-grade aluminum foil (Alcomet, Aluminum foil $8011 \mathrm{~A}$ ) as a primary support for storing cryo preserved human donor skin. This procedure is in use in our skin bank since 1991. We process about 65 skin donors each year. This quantity covers the need of the Brussels burn wound centre. The storage time in our skin bank ranges in practice from 1 month to 1 year. Since the beginning of our activities, cryo donor skin retain samples were taken and stored for future use in safety and quality related tests.

Tissue banking is a field in which an intensive and worldwide growth and exchange is emerging. 
In order to safeguard quality and safety, controlled and validated standard operating procedures are needed. A recent inspection by the Belgian Competent Authority raised the question whether 'foodgrade' aluminum foil is suitable for use in our donor skin cryo preservation procedure. To be more specific, we were asked whether the possible release of aluminum and/or heavy metal contaminants from the food-grade aluminum foil into the cryo preservation medium could have a negative impact on the quality of the cryo preserved donor skin and subsequently on the recipient patient.

With this short communication we try to answer this pertinent question in a pragmatic way.

Aluminum was the principal targeted analyte, but some relevant heavy metal contaminants like arsenic (As), cadmium $(\mathrm{Cd})$, chromium $(\mathrm{Cr})$ and lead $(\mathrm{Pb})$ were also taken into account, because they are known to be present, in trace element quantities, in the considered aluminum foils.

To investigate this issue we proceeded as follows. First, a quantitative analysis of the above mentioned metals in skin cryo preservation medium, retrieved from stored retain samples, was performed. Second, a histological analysis of the stored cryo preserved donor skin was performed in comparison to fresh human skin. Third, we questioned burn surgeons, who had used our cryo preserved skin on their patients since 1991, about any aluminum or heavy metal related adverse (clinical) reactions.

\section{Materials and methods}

\section{Donor skin packaging}

Donor skin (Fig. 1) is impregnated, for $30 \mathrm{~min}$, in cryo preservation medium $(30 \%$ (v/v) glycerol in physiological water) and transferred to a food-grade aluminum foil support (Fig. 2). The donor skin is in direct contact with the aluminum foil support.

Each aluminum foil support holds approximately $300 \mathrm{~cm}^{2}$ of donor skin. After addition of an extra $5 \mathrm{ml}$ of cryo preservation medium, each aluminum foil support is folded and seal-packed in a Class IIa laminated aluminum pouch (Fig. 3), which provides for an extra mechanical protection during the longterm storage of the skin grafts (Fig. 4) in the vapor phase of liquid nitrogen $\left(<-135^{\circ} \mathrm{C}\right)$.

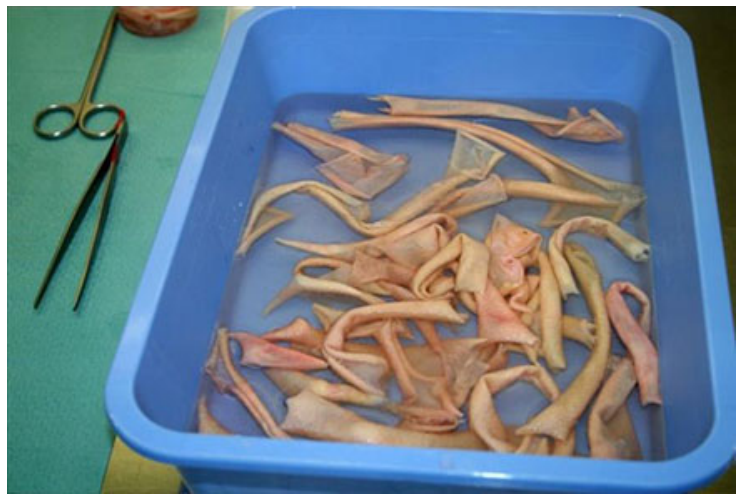

Fig. 1 Fresh donor skin impregnation in cryo medium

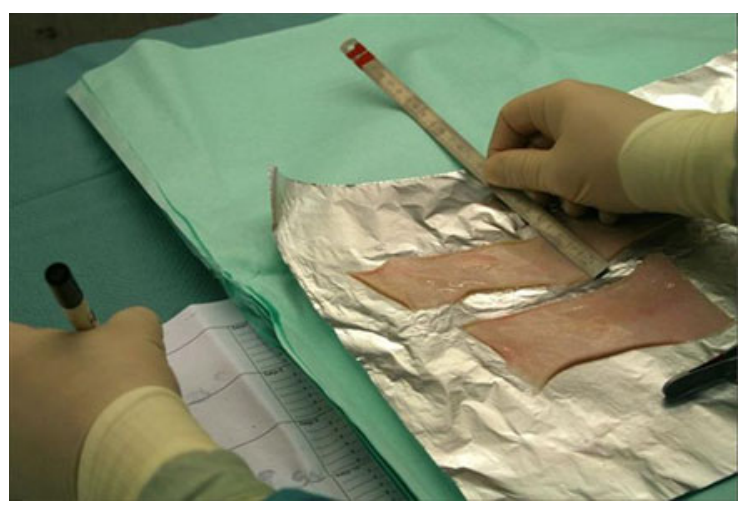

Fig. 2 Donor skin on food-grade aluminum foil support

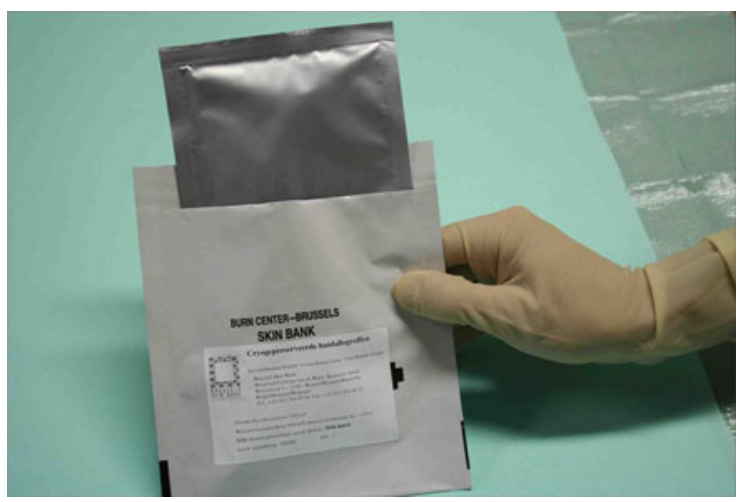

Fig. 3 Donor skin seal-packed in double pouch

Quantitative detection of metal contaminants

\section{Set up 1}

Metal contaminants ( $\mathrm{Al}, \mathrm{As}, \mathrm{Cd}, \mathrm{Cr}, \mathrm{Pb}$ ) were quantitatively measured in the individual cryo 


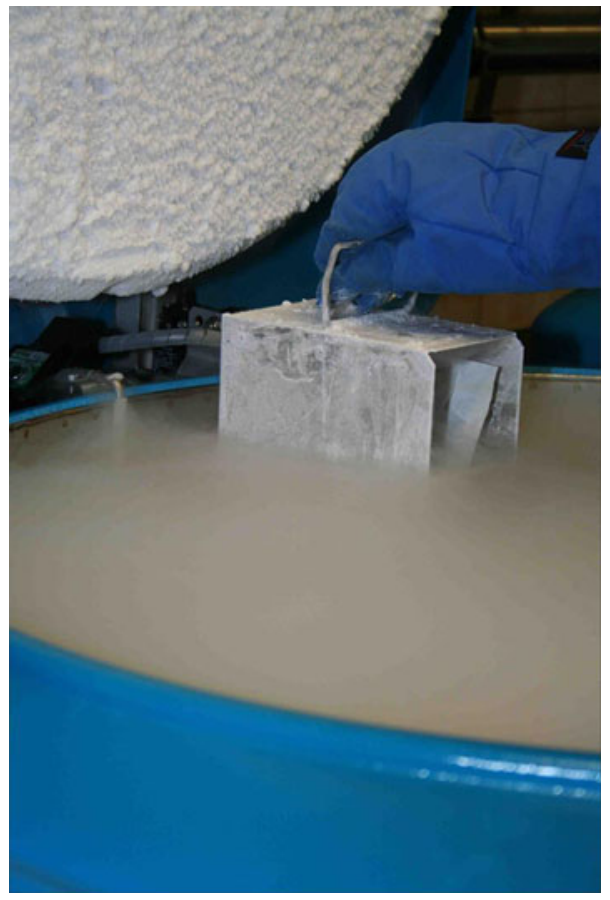

Fig. 4 Donor skin stored in vapor phase of liquid nitrogen

preservation media from 10 donor skin retain samples (10 donors), with storage times ranging from $20 \mathrm{~h}$ to 10 years, using graphite furnace atomic absorption spectrometry (GFAAS).

\section{Set up 2}

Aluminum was quantitatively measured in the pooled cryo preservation medium from seven donor skin retain samples (7 donors), with a storage time of 10 years, using inductively coupled plasma atomic emission spectrometry (ICP-AES).

Cryo preservation medium that had not been in contact with food-grade aluminum foil and did not have contact with cryo preserved donor skin either was used as a control sample in both set ups.

Histological analysis

The retain skin samples from set up 1 (see section above) were fixated in formol at $10 \%$ and sent to the pathological anatomy service for histological analysis. Two stains were carried out; a classical haematoxylin eosin staining for the evaluation of the general cellular structure followed by a periodic acid
Shiff reaction (PAS), which allows a thorough evaluation of the skin basal membrane.

An experienced dermato-pathologist performed a blind microscopic evaluation of the structural integrity of the skin retain samples in comparison to fresh skin samples. This evaluation was based on the pigmentation, presence and integrity of hair follicles and their associated muscles, sweat and sebaceous glands, and the dermal-epidermal junction. The skin samples were also screened for the presence of apoptotic and/or necrotic cells, sentinels of local tissue stress and inflammation.

\section{Clinical evaluation}

Burn surgeons (16), who had used our donor skin during the past 15 years, were contacted and questioned by the actual Medical Director of the Skin Bank about any aluminum or heavy metal related adverse (clinical) reactions, using a standardized questionnaire. Allergic reactions, intoxications, irritations, other?

\section{Results}

Chemical analysis

The GFAAS measurements of $\mathrm{Al}, \mathrm{As}, \mathrm{Cd}, \mathrm{Cr}, \mathrm{Pb}$ in the cryo preservation media of 10 donor skin retain samples are shown in Table $1 . \mathrm{Al}, \mathrm{As}$ and $\mathrm{Pb}$ were not detected (below detection limit), while $\mathrm{Cd}$ and $\mathrm{Cr}$ were detected in trace element quantities (ppm, mg/l).

The ICP-AES measurements of $\mathrm{Al}$ in the pooled cryo preservation medium of seven donor skin retain samples, all dating from 10 years old, are shown in Table 2. Aluminum was detected at a concentration of $1.4 \mathrm{mg} / \mathrm{l}$.

Histological analysis

The histological analysis revealed no differences between the cryo preserved donor skin retain samples and fresh skin (Fig. 5).

Hair follicles and sweat and sebaceous glands were clearly present and intact in the cryo preserved skin. The cryo preserved skin harbored no apoptotic or necrotic cells and showed a normal pigmentation and an intact dermal-epidermal junction. 
Table 1 Aluminum and other metal concentrations in skin cryo preservation medium retain samples

\begin{tabular}{|c|c|c|c|c|c|c|}
\hline Donor ref. & Contact time & Aluminum (Al) & Arsenic (As) & Cadmium $(\mathrm{Cd})$ & Chromium (Cr) & Lead $(\mathrm{Pb})$ \\
\hline \multicolumn{7}{|c|}{ GFAAS technology $(\mathrm{mg} / \mathrm{l})$} \\
\hline BSB-08 067 & $21.5 \mathrm{~h}$ & $\mathrm{bdl}^{\mathrm{a}}$ & bdl & bdl & bdl & bdl \\
\hline BSB-08 068 & 3 Days & bdl & bdl & bdl & 0.0016 & bdl \\
\hline BSB-08 053 & 15 Weeks & bdl & bdl & bdl & 0.0111 & bdl \\
\hline BSB-08 056 & 14 Weeks & bdl & bdl & bdl & 0.0029 & bdl \\
\hline BSB-08 062 & 10 Weeks & bdl & bdl & bdl & bdl & bdl \\
\hline BSB-98 001 & 10 Years & bdl & bdl & bdl & 0.0242 & bdl \\
\hline BSB-98 003 & 10 Years & bdl & bdl & 0.0045 & 0.0218 & bdl \\
\hline BSB-98 004 & 10 Years & bdl & bdl & 0.001 & 0.0085 & bdl \\
\hline BSB-98 007 & 10 Years & bdl & bdl & 0.003 & 0.018 & bdl \\
\hline BSB-98 008 & 10 Years & bdl & bdl & 0.0045 & 0.0108 & bdl \\
\hline \multirow[t]{7}{*}{ BLANC } & BLANC & bdl & bdl & bdl & 0.0042 & bdl \\
\hline & & & & & Detection limits & ppm (mg/l) \\
\hline & & & & & Aluminum & $0.040-2000$ \\
\hline & & & & & Arsenic & $3-150$ \\
\hline & & & & & Cadmium & $0.02-3$ \\
\hline & & & & & Chromium & $0.06-15$ \\
\hline & & & & & Lead & $0.10-30$ \\
\hline
\end{tabular}

${ }^{\text {a }}$ bdl below detection limit

Table 2 Aluminum concentration of the seven pooled skin cryo preservation medium retain samples

\begin{tabular}{lll}
\hline Donor ref. & Contact time & Aluminum $(\mathrm{Al})$ \\
\hline ICP-AES technology & $(\mathrm{mg} / \mathrm{l})$ & \\
BSB-99 001 & 10 Years & 1.4 \\
BSB-99 003 & 10 Years & \\
BSB-99 004 & 10 Years & \\
BSB-99 005 & 10 Years & \\
BSB-99 006 & 10 Years & \\
BSB-99 007 & 10 Years \\
BSB-99 010 & 10 Years \\
BLANC & BLANC & bdl $^{\mathrm{a}}$ \\
\hline
\end{tabular}

Detection limit Al: $100 \mu \mathrm{l} / 1$

${ }^{\text {a }} b d l$ below detection limit

Aluminum foil contact times (storage from $20 \mathrm{~h}$ to 10 years) had no impact on the results.

Clinical evaluation

No adverse reactions (e.g. hypersensitive reactions or signs of intoxication) related to the presence of

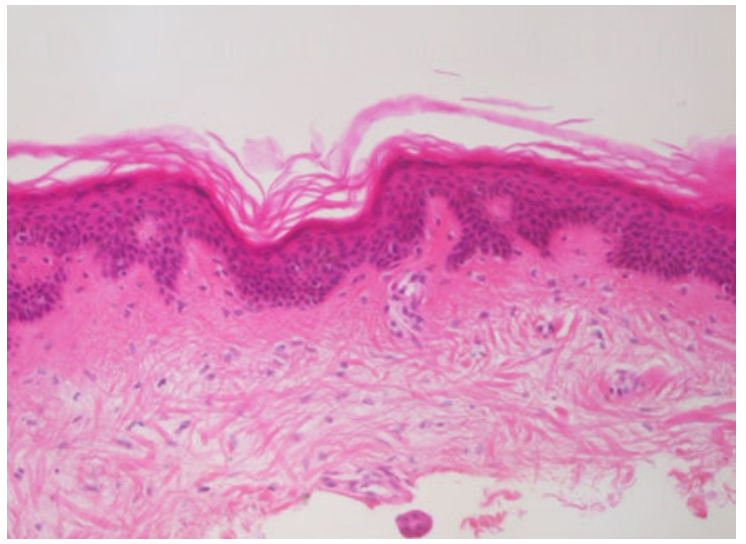

Fig. 5 Donor skin section $(200 \times$, haematoxylin eosin staining and PAS reaction) after 10 years cryo storage

aluminum or heavy metal traces in the grafts were reported.

\section{Discussion}

According to the European Medical Device Directive (MEDDEV), packaging materials for human cells 
and tissues for human application should be certified Class IIa Medical Devices. Specific human cells and tissues need specific (tailor made) packaging materials. For some specific applications, like the cryo preservation of skin, suitable Class IIa packaging materials are not available on the market.

In those cases regulatory bodies should accept the use of non-Class IIa (e.g. food-grade) products, pending the eventual development and commercialization of adequate Class IIa materials. A proper validation of the adequacy of these non-Class IIa materials in the specific application is, however, warranted.

The cryo preservation solution is removed by an obligatory procedural rinsing step before clinical use and is therefore only indicative for the level of absorption of aluminum and/or heavy metals in the tissue, which is in turn only indicative for the adsorptions of these contaminants in the recipient patient. The final absorption levels of aluminum foil related contaminants in the patients is bound to be procedure and tissue dependent.

The timely and quantitative analysis of serum or plasma aluminum and heavy metal levels in the recipients of grafts that were in contact with aluminum foil could once and for all resolve this issue. Aluminum serum/plasma levels are indicative for recent high aluminum exposure or uptake by a person or an animal (Kausz et al. 1999; Ghori and Yaqub 1999; Klein et al. 1993; Tietz 1926).

The aluminum and heavy metal levels in the skin cryo preservation solution, however, are very low (below the detection limit or trace element quantities), even after an unusually long contact time (10 years), and therefore suggest that the contaminant levels in the recipient patient are probably negligible.

In the past, sterilized food-grade aluminum foil was often used as a primary wound dressing. Aluminum foil therapy was introduced by Steinhardt in 1924 and since then it was mostly used in burns but also in ulcers. The advantages of aluminum foil dressings, which were historically described are: readily available (Johns 1949; Hambury 1957), easy to sterilize (Johns 1949; Hambury 1957), non-toxic (Johns 1949; Hambury 1957), absence of sensitivity reactions (Hambury 1957), non-expensive (Johns 1949; Hambury 1957), easy to apply (Johns 1949), prevents crust formation (McAvoy et al. 1979), bacteriostatic (Haeger 1963), non-adherent to sutures (Southwood 1951; McAvoy et al. 1979) and comfortable for the patients (Johns 1949; Southwood 1951;
McAvoy et al. 1979). In 2005, Muneuchi et al. successfully treated gangrene as a result of malignant rheumatoid arthritis with aluminum foil combined with bFGF (Muneuchi et al. 2005). In the seventies, Poole and colleagues measured no significant upsurge in serum or plasma aluminum levels in patients in whom sterilized food-grade aluminum foil was used as a temporary wound dressing (Poole et al. 1979).

In addition we would like to stress that aluminum is the most abundant metallic element on Earth and this since the origin of life. No aluminum-specific biological function has been reported, neither were significant intoxications, with the exception of some Chronic Renal Failure situations (D'Haese et al. 1999). A recent study showed that there is no association between the aluminum content of bone and mortality risk (Hellstrom et al. 2008).

While aluminum has been described as a potential trigger of apoptosis (Ganrot 1986; Franchini et al. 2009), an histological evaluation did not reveal any sign of this process in our cryo preserved skin tissue.

\section{Conclusion}

The small amounts of aluminum and heavy metals that leached into the cryo preservation medium had no effect on the quality of the cryo preserved donor skin allograft. A retrospective analysis revealed no relevant adverse effects in the recipient patients. A thorough rinsing of cryo preserved donor skin allograft before clinical use remains a mandatory procedural step, even if only to remove the often toxic cryo protectant. Further studies could focus on the determination of aluminum and heavy metal concentrations in human tissue grafts that came into contact with aluminium foil and/or the subsequent plasma/serum levels in the recipient patients.

Open Access This article is distributed under the terms of the Creative Commons Attribution Noncommercial License which permits any noncommercial use, distribution, and reproduction in any medium, provided the original author(s) and source are credited.

\section{References}

D'Haese P et al (1999) Aluminum, iron, lead, cadmium, copper, zinc, chromium, magnesium, strontium, and calcium 
content in bone of endstage renal failure patients. Clin Chem 45:1548-1556

Franchini M, Zanini D et al (2009) Evaluation of cryo preserved donor skin viability: the experienced of the regional tissue bank of Verona. Blood Transfus 7(2): 100-105

Ganrot PO (1986) Metabolism and possible health effects of aluminium. Environ Health Perspect 65:363-441

Ghori MI, Yaqub M (1999) Aluminum $\left(\mathrm{Al}^{+3}\right)$ intoxication in normal humans. Int J Agri Biol 1(4):285-287

Haeger K (1963) Preoperative treatment of leg ulcers with silver spray and aluminum foil. Acta Chir Scand 125: $32-41$

Hambury HJ (1957) Aluminum foil dressing. Med World 87:416-420

Hellstrom H-O, Michaelsson K et al (2008) The aluminium content of bone, and mortality risk. Age Ageing; Research Letters 37(2):217-220

Johns WA (1949) Aluminum foil as a dressing for burns. Va Med Mon 76:640

Kausz AT, Antonsen JE, Herez G et al (1999) Screening plasma aluminum levels in relation to aluminum bone disease among asymptomatic dialysis patients. Am J Kidney Dis 34:688-693

Klein GL, Goldblum RM et al (1993) Increased biliar transferrin excretion following parenteral aluminum administration to rats. Int Pharmacol Toxicol 72:373-376

McAvoy J, Charles DM, Moore GE (1979) A meshed aluminum foil wound dressing system. Annals of plastic surgery. Ann Plast Surg 3(5):469-473

Muneuchi G, Suzuki S, Igawa HH (2005) Aluminum foil treatment combined with basic fibroblast growth factor (bFGF) for gangrene of the fingertip caused by collagen disease. Scand J Plast Reconstr Surg Hand Surg 39: 312-314

Poole MD, Kalus AM, Von Domarus H (1979) Aluminum foil as a wound dressing. Br J Plast Surg 32:145-146

Southwood WFW (1951) Aluminum foil on operation wounds. Lancet 24:969

Tietz NW (1926) Text book of clinical chemistry. WB Saunders Co., Berlin 